\title{
Tétanos secundario a mordedura y arañazo de gato en una paciente previamente vacunada
}

\author{
Alberto Fica, Daniela Gainza y Pablo Ortigosa
}

\section{Tetanus after cat scratch and bites in a previously immunized patient}

Tetanus is declining due to vaccination, professional labor management and appropriate wound care. Tetanus cases have been reported despite immunization. We report the case of a previously healthy 21 years old female patient that presented a mild generalized tetanus requiring admission after mild and recurrent cat scratch and bites. She had received six vaccine shots during childhood, and a booster dose five years earlier after a rabbit bite. Symptoms appeared seven weeks after the last contact, and included headache, muscle spasms and mild opisthotonus. Laboratory evaluation, including CSF analysis and microbiological investigation, as well as imaging studies were all normal. The patient received 6,000 IU of human antitoxin immunoglobulin. No autonomic manifestations or respiratory compromise were registered. Symptoms resolved rapidly and she was discharge after seven days with an order to complete a tetanus toxoid immunization schedule with three doses. Conclusions. Tetanus is possible in urban settings with a declining epidemiologic curve of disease in previously immunized patients. Severity of disease is modulated by previous vaccination.

Key words: Domestic animal, cat, bite, tetanus, tetanus toxoid.

Palabras clave: Animal doméstico, gato, mordedura, tétanos, toxoide tetánico, zoonosis.

\section{Introducción}

$\mathrm{E}$ 1 tétanos es una enfermedad infecciosa inmunoprevenible provocada por la tetanospasmina, una exotoxina de Clostridium tetani que ejerce una inhibición de neurotransmisores inhibidores como el ácido $\gamma$-aminobutírico (GABA). El efecto neto es una hiperactivación de la $\alpha$-motoneurona en el asta anterior de la médula y de neuronas autonómicas, llevando a espasmos musculares e inestabilidad autonómica ${ }^{1-3}$. La toxina es producida luego de que las esporas inoculadas en una herida germinan en el tejido humano y migran por transporte axonal retrógrado y diseminación transináptica hacia el sistema nervioso. Las esporas de este bacilo grampositivo anaerobio son de presencia ubicua en el ambiente y en las deposiciones de los animales. Diferentes tipos de heridas pueden estar involucradas en la génesis del tétanos y de magnitud variable como aquellas asociadas a quemaduras, heridas traumáticas, mordeduras por animales o reptiles, onfalitis del recién nacido, piercing o drogadicción intravenosa ${ }^{4-7}$. En su aparición participa también la falta de un adecuado manejo de las heridas y la ausencia de inmunizaciones pasivas y/o activas que neutralicen la antitoxina ${ }^{5,8,9}$.

Las manifestaciones clínicas del tétanos incluyen fiebre, cefalea, espasmos musculares dolorosos y progresivos, trismus, risa sardónica, espasmo laríngeo, parálisis de los músculos respiratorios y fenómenos autonómicos como hipertensión arterial y arritmias. Los espasmos pueden ser gatillados por ruidos o procedimientos en el paciente. El período de incubación es habitualmente menor a dos semanas, pero puede ser más prolongado llegando a los dos a tres meses. Los períodos más largos tienden a asociarse a heridas más distales o a inóculos menores $^{1}$. En países en vías de desarrollo, la mortalidad puede alcanzar alrededor de $20 \%$ en neonatos y $45 \%$ en adultos $^{3}$. En contraste, en países desarrollados la mortalidad ha disminuido notoriamente hasta cifras cercanas a $0 \%$ en pacientes con plan de inmunización completo ${ }^{10}$. Los cuadros de tétanos se clasifican en cuatro formas: generalizada, localizada, cefálica y neonatal.

El tétanos es una enfermedad en declinación global debido a la atención profesional del parto, de las heridas traumáticas incluyendo mordeduras por animales, y por la incorporación de la vacuna antitetánica en la población infantil y en mujeres embarazadas. En Chile, las tasas han disminuido desde 0,9 a 0,04 casos por 100.000 habitantes entre los años 1963 y el 2014, representando una caída de $95 \%$ en su incidencia (Figura 1) ${ }^{11,12}$. Debido a la alta mortalidad de los cuadros de tétanos y su difícil manejo, la estrategia básica de prevención es la inmunización activa de la población en edades tempranas. En Chile se aplican actualmente seis dosis de vacunas contra el tétanos, las que se administran desde la lactancia hasta el término del
Hospital Militar de Santiago, Santiago, Chile. Servicio de Infectología (AF) Servicio de Medicina (DG). Universidad de los Andes, Chile.

Programa Formación Medicina Interna (PO).

Conflicto de interés: ninguno. Financiamiento: ninguno.

Recibido: 3 de septiembre de 2016

Aceptado: 28 de febrero de 2017

Correspondencia a:

Alberto Fica C.

albertoficacubillos@gmail.com 


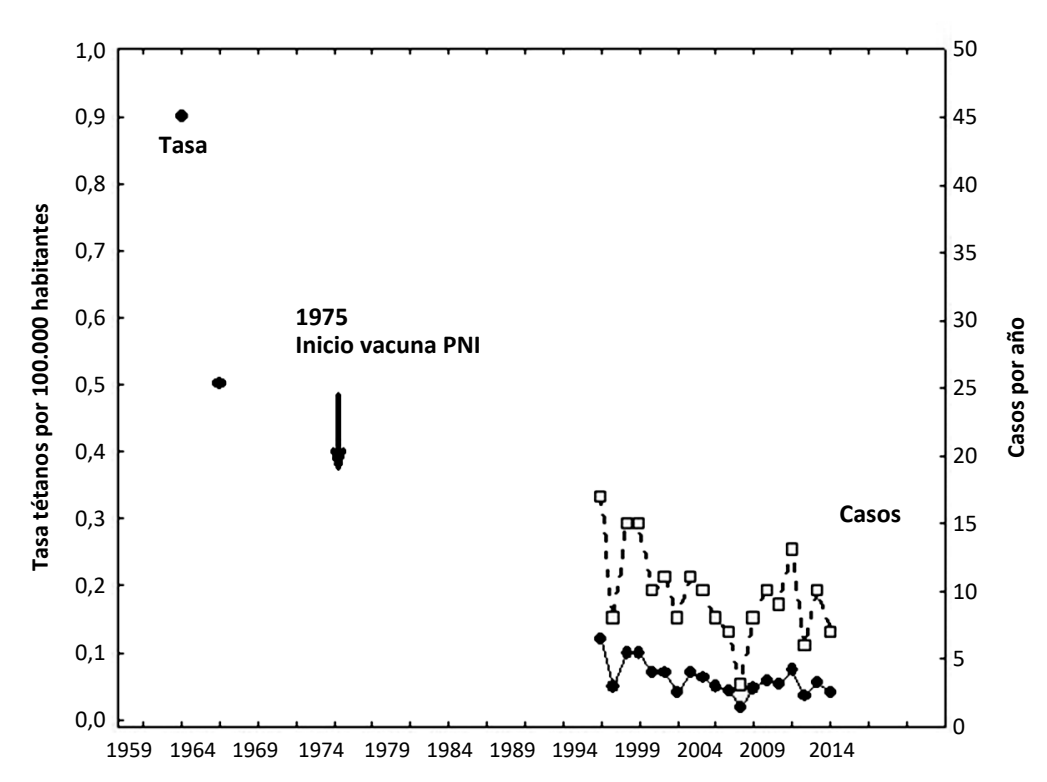

Figura 1. Tasa y casos anuales de tétanos en Chile. Fuente: Departamento de Estadísticas en Información en Salud, Ministerio de Salud, Chile. PNI: Programa Nacional de Inmunizaciones.

ciclo de educación básica. Esta medida de salud pública se inició el año 1975. No más de una decena de casos se reportan en nuestro país anualmente, convirtiéndola en una rareza clínica lo que a su vez impide la sospecha inicial. Nuestra incidencia es similar a lo registrado en países desarrollados como Canadá2.

La percepción de que la vacuna es eficaz para prevenir esta infección conspira contra su sospecha en personas inmunizadas a pesar de que existen reportes sobre casos de tétanos en pacientes previamente inmunizados. Aproximadamente, $60 \%$ de los casos registrados en E.U.A. tienen antecedentes de vacuna y cerca de $10 \%$ ocurre en personas con $\geq 4$ dosis $^{5}$. En línea con estos antecedentes, algunos estudios han demostrado que pacientes con esquemas completos logran niveles de anticuerpos antitetánicos protectores sólo en $72 \%$ de los individuos mayores de seis años ${ }^{13}$.

El propósito de esta comunicación es presentar un caso clínico de tétanos generalizado leve en una paciente joven con sus vacunas al día y un refuerzo recibido cinco años antes.

\section{Caso clínico}

Paciente de sexo femenino de 21 años, estudiante universitaria, residente en la ciudad de Santiago y sin antecedentes mórbidos de importancia. Consultó por primera vez al Servicio de Urgencia por dos días de cefalea, mialgias, sensación nauseosa y odinofagia. Se interpretó el cuadro como una infección viral indicándose manejo sintomático; sin embargo, consultó por segunda vez $48 \mathrm{~h}$ más tarde por cefalea holocránea intensa y odinofagia. El cuadro cedió con metamizol, paracetamol y ketoprofeno i.v. y fue dada de alta, aunque volvió a consultar ese mismo día por reaparición de los síntomas. El examen físico consignó ausencia de signos meníngeos y una paciente lúcida. Los síntomas nuevamente cedieron a la terapia parenteral analgésica combinada. Volvió por cuarta vez, a los cuatro días de haberse iniciado los síntomas. Se solicitó una tomografía computada (TC) de cerebro y de vasos cervicales y cerebrales que no mostró anormalidades. Sin embargo, por la persistencia de los síntomas se decidió internar a la paciente. El examen físico no revelaba anormalidades. Su temperatura axilar era normal $\left(36,6^{\circ} \mathrm{C}\right)$, al igual que su presión arterial $(132 / 78 \mathrm{mmHg})$ y oximetría de pulso ( $97 \%$ ambiental) pero demostraba una leve tendencia a la taquicardia (96/min).

$\mathrm{Al}$ examen neurológico destacaba una paciente inquieta y asustada, con espasmos y curvatura de la columna dorso lumbar (opistótonos leve y transitorio) al evaluar signos meníngeos o al palpar la columna. Además, presentó una contracción cervical y lumbar intensa y súbita al efectuar una prueba de sonido en la pieza (aplauso). Su nivel de conciencia era normal y no había otras anormalidades al examen físico. Refería fotofobia; sin embargo, la exposición a la luz no generó espasmos o contracciones musculares involuntarias como las descritas previamente.

En forma dirigida se interrogó a la paciente por traumatismos, tatuajes o piercing sin encontrar exposiciones de este tipo. Tampoco acusaba consumo de fármacos o drogas, viajes recientes o vacunas. No obstante, indicó haber sufrido múltiples rasguños y mordeduras de su gato doméstico durante dos meses hasta unas siete semanas antes del inicio de sus síntomas. Estas lesiones ocurrieron en las manos y muslos y algunas de ellas sangraron, aunque no buscó atención médica por ellas. Posteriormente su mascota falleció por un ataque canino. La paciente había recibido un refuerzo de toxoide antitetánico cinco años antes por una mordedura de conejo.

El estudio inicial reveló pruebas de laboratorio normales en la serie roja, glóbulos blancos, plaquetas, pruebas de función renal, hepática y valores bioquímicos en sangre, incluyendo calcemia $(10 \mathrm{mg} / \mathrm{dL})$. Además, el estudio del LCR demostró un líquido incoloro sin pleocitosis, con glucorraquia y proteinorraquia normales. Exámenes complementarios del LCR para virus de la familia herpes por RPC fueron todos negativos, al igual que los valores de adenosindeaminasa en este fluido. El test de tinta china y la tinción de Ziehl Neelsen en LCR también resultaron negativos. Adicionalmente, las pruebas en sangre para VIH, sífilis e infección por Mycoplasma también fueron negativas y los cultivos de LCR no demostraron crecimiento bacteriano. La paciente no tenía antecedentes 
de consumo de drogas que pudiesen inducir espasmos, rigidez muscular o inestabilidad hemodinámica como las fenotiazinas o neurolépticos y tampoco una infección dental. Al examen de ingreso no se detectó ningún foco infeccioso.

Debido a la fuerte sospecha de un tétanos generalizado (opistótonos), la paciente fue trasladada a una Unidad de Tratamiento Intermedio para observación, en un ambiente protegido de ruidos y luz y se le administraron 6.000 UI de inmunoglobulina antitetánica humana, distribuyendo las inyecciones en cinco sitios intramusculares diferentes. El score de gravedad de Dakar dio 1 punto (máximo 6) y el score de gravedad del tétanos o TSS por su sigla en inglés (tetanus severity score) fue de -3 puntos (grave $\geq$ 8 puntos), respectivamente, indicando en ambos casos, un cuadro leve. La paciente no recibió antibacterianos.

La paciente evolucionó con una rápida regresión de sus molestias en las primeras $72 \mathrm{~h}$. Disminuyó la cefalea intensa, la angustia, la irritabilidad ante el ruido y la luz, la tendencia al opistótonos y las contracciones cervicales con el ruido. Por su buena evolución fue dada de alta a los siete días de su ingreso. En el primer control ambulatorio a la semana del alta, persistía con cierto grado de rigidez muscular global que se manejó con clonazepam. Un seguimiento al mes del alta reveló una paciente totalmente normal. Se le indicó recibir tres dosis de vacuna antitetánica.

\section{Discusión}

El tétanos es una enfermedad común en los países en desarrollo y que causa cerca de 500.000 muertes al año. Constituye una amenaza especialmente para las personas no vacunadas. Aparte de los antibacterianos y la antitoxina, no tiene terapia específica y su tratamiento es esencialmente de soporte, requiriendo algunos pacientes ingreso a UCI. Su letalidad va entre 12 y $53 \%{ }^{14}$. En Chile, los casos se concentran en personas mayores y en el sur del país, en zonas rurales ${ }^{12}$. Por su baja frecuencia, la sospecha es reducida lo que favorece una mayor letalidad por el manejo inapropiado inicial ${ }^{8}$.

Creemos que el caso presentado corresponde a un tétanos debido a sus manifestaciones clínicas compatibles, antecedente de lesiones recurrentes provocadas por un animal, ausencia de diagnósticos alternativos y una rápida respuesta al uso de inmunoglobulina antitetánica.

El caso presentado deja varias enseñanzas que merecen ser comentadas. Por ejemplo, a pesar de su declinación epidemiológica y la vacunación de la población, los casos de tétanos siguen siendo posibles de observar y requieren un alto grado de sospecha. En este caso el antecedente de tenencia de mascotas permitió identificar una exposición traumática considerada menor por la paciente pero recurrente en el tiempo. La misma anamnesis descartó otro tipo de heridas traumáticas, drogadicción intravenosa, tatuajes o piercing. La baja magnitud del trauma cotidiano explica la no concurrencia a una consulta médica y la posibilidad de recibir un inóculo en forma repetida. La sospecha se planteó por la exposición de riesgo junto a un cuadro agudo de cefalea con espasmos musculares recurrentes, tendencia al opistótonos al buscar signos meníngeos y el desencadenamiento paroxístico de espasmos en la región cervical mediante una prueba de ruido, aun en ausencia de trismus, risa sardónica o trastornos respiratorios. Las consultas frecuentes antes del ingreso, resaltan la difícil sospecha inicial del cuadro como ha ocurrido en otros $\operatorname{casos}^{8}$, las que además se concentraron en el manejo de la cefalea.

La vacuna tiene una alta eficacia protectora $(>80 \%)$ según se desprende de las cifras observadas en soldados norteamericanos durante la Segunda Guerra Mundial en comparación al período prebélico ${ }^{15}$. Se ha establecido mediante modelos animales de neutralización de toxina (en caballos, cobayos o ratones) que títulos $\geq 0,01 \mathrm{UI} / \mathrm{mL}$ serían protectores sobre el desarrollo de tétanos letal ${ }^{9,15,16}$. Asimismo, la autoexposición a dosis letales humanas de toxina en dos investigadores con niveles basales de anticuerpos de 0,005 y $0,01 \mathrm{UI} / \mathrm{mL}$, no se asoció al desarrollo de síntomas lo que respaldó la creencia de un nivel protector ${ }^{15}$. En los años 70, investigadores franceses lograron establecer que los casos graves se observaron en pacientes con $<0,01 \mathrm{UI} / \mathrm{mL}$ y los casos letales con títulos $\leq 0,002 \mathrm{UI} / \mathrm{mL}^{17}$. Además, describieron que los pacientes con un antecedente de vacunación muy remoto, registraban títulos muy bajos ${ }^{17}$. En Chile, no se efectúa determinación de anticuerpos.

Como en nuestro caso, en las últimas décadas se han descrito casos de tétanos en personas con varias dosis de vacuna, incluso con esquemas completos con refuerzo y a pesar de presentar títulos de anticuerpos sobre el umbral protector definido previamente ${ }^{7,16,18-22}$. Como se comentó más arriba, series de E.U.A. indican que cerca de $60 \%$ de los casos tienen dosis previas de vacunas y $10 \%$ incluso cuatro o más dosis ${ }^{5}$. En la Tabla 1 se presentan los casos publicados en las últimas décadas que fueron observados en pacientes previamente vacunados o en hijos de madres vacunadas. A pesar de la eficacia incompleta de la vacuna, existe una clara tendencia a que los casos de tétanos en personas previamente vacunadas sean menos graves y letales tal como sucedió en nuestro caso ${ }^{5,14-16,18-20}$. Así, en algunas clasificaciones de gravedad, el antecedente de vacunación y su antigüedad aparecen incorporados en la predicción de sobrevida ${ }^{3}$. De los puntajes de predicción de riesgo, el único validado prospectivamente es el TSS que asigna un desenlace fatal si es $\geq 8$ puntos ${ }^{14}$. La puntuación de Dakar tiene un máximo de 6 puntos y su desempeño es discretamente inferior al TSS (área bajo la curva 0,89 versus 0,80 ; respectivamente $)^{14}$. En línea con esta evidencia 


\begin{tabular}{|c|c|c|c|c|c|c|c|}
\hline Año & $\mathbf{n}$ & Escenario & $\begin{array}{l}\text { Período de } \\
\text { incubación }\end{array}$ & Vacuna previa & Títulos UI/mL* & Desenlace & Referencia \\
\hline 1972 & 13 & Serie de casos & & $\geq 25$ años & $<0,002 \mathrm{a}<1$ & No precisado & 17 \\
\hline 1978 & 1 & 우 25a, drogadicción ev & & Refuerzo hace 15 años & 0,04 & Vivo & 18 \\
\hline 1986 & 1 & $\widehat{\sigma}, 35 \mathrm{a}$, herida en pie & 3 días & Refuerzo hace 4 años & 0,16 & Vivo & 16 \\
\hline 1991 & 9 & Tétanos neonatal & & 1-3 dosis en embarazo & $0,04-4,2$ & No reportado & 21 \\
\hline 1995 & 6 & Tétanos neonatal & & $\geq 2$ dosis en embarazo & $0,28-3,43$ & 3 fallecen & 22 \\
\hline 2000 & 1 & đa, 45a, drogadicción ev & & Desconocido & 0,16 & Fallece & 7 \\
\hline 2005 & 1 & ㅇ 7a, herida en la mano & 10 días & Esquema completo & 0,17 & Vivo & 20 \\
\hline 2014 & 1 & o $31 \mathrm{a}$, herida en la mano & 10 días & Refuerzo hace 13 años & 8,4 & Vivo & 19 \\
\hline 2017 & 1 & 우 21a, mordedura gato & 7 semanas & Refuerzo hace 5 años & - & Vivo & Este trabajo \\
\hline
\end{tabular}

nuestra paciente presentó una baja puntuación con ambos sistemas y evolucionó con un cuadro leve. Se ha planteado que las razones que explican la aparición de tétanos en pacientes vacunados residen en el tamaño del inóculo que impide el efecto neutralizante de los anticuerpos. Así, el antecedente de vacunación o refuerzo, no debe ser impedimento para sospechar un caso de tétanos si el cuadro clínico es compatible y la exposición de riesgo emerge en la entrevista médica.

El período de incubación en nuestro caso fue prolongado, cercano a los dos meses, lo que puede estar relacionado a la posición distal de las heridas y posiblemente al tamaño del inóculo. En personas previamente vacunadas los períodos de incubación no necesariamente son prolongados (Tabla 1).

Otros aspectos a destacar incluyen el escenario urbano de nuestro caso y la juventud del caso, aspectos que no coinciden con los casos observados en Chile en las últimas décadas, estableciendo así un escenario epidemiológico menos predecible ${ }^{12}$.

El diagnóstico diferencial del tétanos generalizado es limitado e incluye efectos adversos a fármacos capaces de generar inestabilidad hemodinámica, rigidez o espasmos musculares como los neurolépticos y fenotiazinas. La intoxicación por estricnina puede producir un cuadro similar, provocado por el consumo de veneno para ratas y presenta un corto período de incubación con contracciones y convulsiones. Puede confirmarse por la detección del compuesto en fluidos. Finalmente, las infecciones dentales pueden constituir el foco asociado al cuadro de tétanos o generar trismus como parte del diagnóstico diferencial. Estos diagnósticos alternativos fueron descartados en nuestra paciente por anamnesis y examen físico. El apoyo del laboratorio al diagnóstico es secundario ya que los cuadros de tétanos se reconocen por sus manifestaciones clínicas. No siempre es posible reconocer una infección y su cultivo sólo ocasionalmente revela la presencia de $C$. tetani. De existir la sospecha podría solicitarse la medición o detección de fenotiazinas o estricnina en fluidos ${ }^{16}$.

El manejo del tétanos se basa en el control del foco infeccioso con aseo de la herida y antibacterianos, en la observación directa del paciente, terapia de soporte, neutralización de la toxina libre circulante mediante inmunoglobulina humana antitetánica y en la vacunación con toxoide tetánico ya que la infección natural no deja inmunidad. Así, el desbridamiento de la herida es fundamental para remover el foco productor de toxina junto a la aplicación de alguno de los varios antimicrobianos activos sobre C. tetani. Sin embargo, este ítem del tratamiento no revierte el efecto neurotóxico de la toxina ya adsorbida en las neuronas.

La estructura de la penicilina es similar al GABA, el principal neurotransmisor inhibitorio del SNC y este antibiótico puede actuar como un antagonista competitivo del GABA facilitando un estado excitatorio ${ }^{3}$. Ello ha llevado a postular que metronidazol podría ser una mejor alternativa terapéutica cuando se requiere el concurso de una terapia antimicrobiana. Al menos dos estudios aleatorizados controlados y uno abierto han sido efectuados comparando las tasas de mortalidad entre penicilina y metronidazol. A pesar de una menor mortalidad en el grupo tratado con metronidazol en éste último, los estudios controlados no lograron demostrar diferencias en el desenlace, lo que no permite descartar el uso de penicilina como opción terapéutica ${ }^{3,23,24}$.

La observación directa del paciente y la terapia de 
soporte está destinada al manejo oportuno de las complicaciones respiratorias y hemodinámicas como la hipertensión, hipotensión arterial o arritmias. A veces se requiere una traqueostomía y conexión a ventilación mecánica. Por ello, la fase inicial del manejo debe ser efectuada en una unidad intensiva o intermedia para efectuar un tratamiento oportuno y monitorizar la aparición de las complicaciones. En nuestro caso aplicamos la máxima dosis terapéutica recomendada de inmunoglobulina antitetánica (6.000 UI), la que debió ser administrada en varios sitios por vía intramuscular. Esta estrategia impidió comenzar con el esquema protector de vacuna antitetánica por falta de sitios de inoculación, quedando postergada para después del alta. Las medidas preventivas fueron complementadas con una educación sobre la enfermedad y consejos para evitar la re-exposición al riesgo. Debido a que la infección aguda no confiere inmunidad, todo paciente que ha sufrido tétanos debe recibir una inmunización activa con 3 dosis.

En conclusión, los casos de tétanos pueden ser observados en pacientes jóvenes previamente vacunados y en ambientes urbanos en países con tasas en declinación. La vacunación previa y los refuerzos permiten que estos casos sean de carácter leve y buen pronóstico.

\section{Resumen}

El tétanos está en declinación gracias a la vacunación, manejo profesional del parto y el cuidado apropiado de las heridas. Se han reportado casos a pesar de la inmunización. Presentamos el caso clínico de una mujer previamente sana de 21 años que presentó un tétanos generalizado leve, luego de repetidas mordeduras y arañazos de su gato. Había recibido su esquema completo de seis dosis de vacuna antitetánica en la infancia y un refuerzo hacía cinco años luego de una mordedura por conejo. Los síntomas aparecieron siete semanas después del último contacto e incluyeron cefalea, espasmos musculares y opistótonos leve. La evaluación de laboratorio, incluyendo un estudio del LCR e imágenes fueron normales. La paciente recibió inmunoglobulina humana antitetánica. No hubo manifestaciones autonómicas ni compromiso respiratorio. Los síntomas regresaron rápidamente y se dio de alta a los siete días con indicación de completar tres dosis de vacuna antitetánica. Conclusiones: El tétanos es posible en ambientes urbanos con una curva epidemiológica en descenso en pacientes previamente inmunizados. La gravedad del cuadro es modulada por la vacunación previa.

\section{Referencias bibliográficas}

1.- $\quad$ Reddy P, Bleck T P. Clostridium tetani (Tetanus). Chapter 244. Mandell GL, Bennett JE, Dolin R. Editors. Mandell, Douglas, and Bennett's Principles of Practices of Infectious Diseases, $7^{\text {th }}$ Ed, Philadelphia: Curchill Livingstone Elsevier 2010; p. 3091-6.

2.- Dhalla S. Postsurgical tetanus. Can J Surg 2004; 47: 375-9.

3.- Farrar J J, Yen L M, Cook T, Fairweather N, Bihn N, Parry J, et al. Tetanus. J Neurol Neurosurg Psychiatry 2000; 69: 292-301.

4.- Armijo J, Soto-Aguilar F, Brito C. Tétanos generalizado: caso clínico y revisión del tema. Rev Chil Neuro-Psiquiatr 2012; 50: 229-33.

5.- Centers for Disease Control and Prevention. Tetanus surveillance-United States, 2001-2008. MMWR Morb Mortal Wkly Rep 2011; 60: 365 9.

6.- Ledermann W. La alfarecería y los primeros casos de tétanos neonatal descritos en Chile en 1894. Rev Chilena Infectol 2011; 28: 599-602.

7.- Abrahiam F M, Pollak C V Jr, LoVecchio F, Nanda R, Carlson R W. Fatal tetanus in a drug abuser with "protective" antitetanus antibodies. J Emerg Med 2000; 18: 189-93.

8.- Grez M, Gatica E, Ceroni L. Tétanos en consulta de urgencia: ¿mito o realidad? Rev Chil Cir 2004; 56: 71-3.
9.- McComb J A. The prophylactic dose of homologous tetanus antitoxin $\mathrm{N}$ Engl J Med 1964; 270: 175-8.

10.- Pascual F B, McGinley E L, Zanardi L R, Cortese M M, Murphy T V. Tetanus surveillance-United States, 1998-2000. MMWR Surveill Summ 2003; 52: 1-8.

11.- Martínez Gallegos P. Actualización de la situación epidemiológica de difteria, tétanos y tétanos neonatal. Vigía (Santiago) 2007; 10 (24): 13-7.

12.- De La Fuente M, González S, Guevara G, Castillo I, Ignatiew I. Epidemiología del tétanos en Chile en los últimos 25 años. Rev Chil Pediatr 1986; 57: 273-7.

13.- McQuillan G M, Kruszon-Moran D, Deforest A, Chu S Y, Wharton M. Serologic immunity to diphtheria and tetanus in the United States. Ann Intern Med 2002; 136: 660-6.

14.- Thwaites C L, Yen L M, Glover C, Tuan P Q, Nga N T, Parry J, et al. Predicting the clinical outcome of tetanus; the tetanus severity score. Trop Med Int Health 2006; 11: 279-87.

15.- Edsall G. Specific prophylaxis of tetanus. J Am Med Assoc 1959; 171: 417-27.

16.- Passen E L, Andersen B R. Clinical tetanus despite a protective level of toxin-neutralizing antibody. JAMA 1986; 255: 1171-3.

17.- Goulon M, Girard O, Grosbuis S, Desormeau J P, Capponi M F Antitetanus antibodies. Assay before anatoxinotherapy in 64 tetanus patients. Nouv Presse Med 1972; 1: 3049-50.

18.- Berger S A, Cherubin C E, Nelson S, Levine L. Tetanus despite preexisting antitetanus antibody. JAMA 1978; 240: 769-70.

19.- Vollman K E, Acquisto N M, Bodkin R P. A case of tetanus infection in an adult with a protective antibody level. Am J Emerg Med 2014; 32: 392.e3-4.

20.- Atabek M E, Pirgon O. Tetanus in a fully immunized child. J Emerg Med 2005; 29: 3456.

21.- Maselle S Y, Matre R, Mbise R, Hofstad T. Neonatal tetanus despite protective serum antitoxin concentration. FEMS Microbiol Immunol 1991; 3: 171-5.

22.- de Moraes-Pinto M I, Oruamabo R S, Igbagiri F P, Chan M C, Prado S M, Vancetto M D, et al. Neonatal tetanus despite immunization and protective antitoxin antibody. J Infect Dis 1995; 171: 1076-7.

23.- Ahmadsyah I, Salim A. Treatment of tetanus: an open study to compare the efficacy of procaine penicillin and metronidazole. Br Med J (Clin Res Ed) 1985; 291: 648-50.

24.- Ganesh Kumar A V, Kothari V M, Krishnan A, Karnad D R. Benzathine penicillin, metronidazole and benzyl penicillin in the treatment of tetanus: a randomized, controlled trial. Ann Trop Med Parasitol 2004; 98: 59-63. 